\title{
Correlation between quality of life and adherence to treatment in hemodialysis patients
}

\author{
Mahin Naderifar ${ }^{1,2}{ }^{\circledR}$, Mansoureh Zagheri Tafreshi ${ }^{{ }^{*}}{ }^{\circledR}$, Mahnaz Ilkhani $^{4}$, Magid Reza Akbarizadeh ${ }^{5}$, Fereshteh \\ Ghaljaei $^{6}$ \\ ${ }^{1}$ School of Nursing and Midwifery, Shahid Beheshti University of Medical Sciences, Tehran, Iran \\ ${ }^{2}$ Department of Nursing, Faculty of Nursing and Midwifery, Zabol University of Medical Sciences, Zabol, Iran \\ ${ }^{3}$ Department of Nursing Management, School of Nursing and Midwifery, Shahid Beheshti University of Medical Sciences, Tehran, Iran \\ ${ }^{4}$ Department of Medical-Surgical Nursing, School of Nursing and Midwifery, Shahid Beheshti University of Medical Sciences, Tehran, Iran \\ ${ }^{5}$ Department of Pediatrics, Faculty of Medicine, Zabol University of Medical Sciences, Zabol, Iran \\ ${ }^{6}$ Community Nursing Research Center, Zahedan University of Medical Sciences, Zahedan, Iran
}

\section{A R T I C L E I N F O}

\section{Article Type:}

Original

\section{Article History:}

Received: 11 October 2017

Accepted: 18 January 2018

Published online: 27 February 2018

\section{Keywords:}

Quality of life

Hemodialysis

Questionnaire

Adherence to treatment

End-stage renal disease

\begin{abstract}
A B S T R A C T
Introduction: Institutionalizing adherence to treatment in hemodialysis patients is one of the important nursing goals for improving quality of life in these patients. Adherence to treatment approach in these patients can play a pivotal role in improving the health level and feeling of well-being.

Objectives: This study aimed at determining the quality of life in hemodialysis patients presenting to hemodialysis centers affiliated to Shahid Beheshti University of Medical Sciences, Tehran, Iran, on the basis of adherence to treatment.

Patients and Methods: This is a correlational descriptive-analytic study. The study population consisted of hemodialysis patients in five hospitals affiliated to Shahid Beheshti University of Medical Sciences, Tehran, in 2017. The data were collected during 8 months from October 2016 to May 2017 in Tehran. A sample volume of 200 patients was determined in this study. Demographic information questionnaire, KDQOL-SF, and ESRD-AQ were applied in data collection. Availability sampling method was used to select the samples on the basis of inclusion criteria. The data were analyzed with SPSS version 18 using descriptive and inferential statistics.

Results: Our findings showed that $50 \%$ of the patients were male. Most of the respondents of the study (23\%) were 51-60 years old. The results indicated that the mean score of quality of life of patients was $50.42 \pm 22.81$. The mean total score of adherence to treatment was $901.13 \pm 85.30$. Also, the correlation coefficient in this study revealed a significant correlation between total score of quality of life and adherence to treatment $(\mathrm{r}=0.218, P<0.01)$.

Conclusion: Considering the significant correlation between adherence to treatment and life quality of patients, healthcare providers can promote the life quality of these patients via focusing on planning programs for emphasizing the role of education and interventions that improve adherence to treatment in these patients.
\end{abstract}

\section{Implication for health policy/practice/research/medical education:}

Nurses and policy makers should have special attention to correlation between quality of life and adherence to treatment in hemodialysis patients. It plays an important role to provide a framework for appropriate supportive measures and gives the opportunity for nurses to manage the problems involving these patients.

Please cite this paper as: Naderifar M, Zagheri Tafreshi M, Ilkhani M, Reza Akbarizadeh M. Correlation between quality of life and adherence to treatment in hemodialysis patients. J Renal Inj Prev. 2019;8(1):22-27. Doi: 10.15171/jrip.2019.05.

\section{Introduction}

The end-stage renal disease characterized by progressive and irreversible degeneration of kidney functioning (1) causes accumulation of toxins, the presence of uremic syndrome and considerable complications in the body. Although recent advancements in medical sciences and the possibility of kidney transplant have opened new horizons to these patients, some of these patients cannot receive 
kidney transplant (2) and require hemodialysis to save their lives (3). The data of US renal information system indicated that about $90 \%$ of the patients affected with this disease undergo hemodialysis. The hemodialysis patients' data increase in Iran by \%15 annually (4). Hemodialysis is not able to treat the disorder and compensate for all the impaired metabolic or endocrine functions of the kidney (2). Additionally, it is associated with the incidence of acute complications (hypotension and/or muscular spasm) and chronic disorders (anemia and viral hepatitis B and C) (5). In addition, the hemodialysis patients often suffer from feelings of having no freedom, dependence on relatives, impaired familial and social life, and reduced or no income (6). Fatigue, lethargy, disability, diminished sexual desire, and even major depression associated with time-consuming and difficult hemodialysis can decrease patients' feeling of well-being (7) and disturb their quality of life (6). It can also cause changes in life style, health status and individual's roles (8). These patients are exposed to numerous physical, mental, and social stressors $(9,10)$. Quality of life is an all-inclusive concept involving various aspects of life such as financial status, occupation, love, religion, and also the physical, mental, and social health. Perception of their status in life with respect to the cultural context and value systems with which they live considering their goals, expectations, standards and concerns (11). Studies conducted in this field indicate alarmingly the weak quality of life in these patients compared to the healthy community (12-14). Paying attention to the life quality of these patients is important since according to some evidence, it is related to medical outcomes such as reduced patient hospitalization and decreased mortality rate related to hospitalization $(15,16)$. One of the problems reported about hemodialysis patients is the deficiency in their adherence to treatment. This term refers to all patient behaviors (diet, fluids and drug administration) aimed at fulfilling the recommendations given by health care-givers $(17,18)$. Lack of compliance with diet is common among the hemodialysis patients so that about $25 \%-86 \%$ of these patients do not comply with their diet (19). Compliance with diet, drug program, and fluid intake constraints are of utmost importance and can play a significant role in improving health level and feeling of well-being in hemodialysis patients $(20,21)$. Any shortcoming in adherence to treatment in these patients often leads to extra para-clinical tests, modified treatment plan, modified prescribed medicines, increased proportion of hospitalization and increased medical costs $(22,23)$. Given the importance of adherence to treatment in hemodialysis patients, several studies have been carried out in various countries. García-Llana et al $(24,25)$ in Spain and Oliveria et al (26) in Brazil investigated quality of life and adherence to treatment of these patients. However, a review of the related studies in Iran demonstrated that no study has comprehensively and simultaneously surveyed the life quality and adherence to treatment in these patients despite the important role of the effect of adherence to treatment on quality of life in these patients.
Of course, the status quality of life and adherence to treatment have been examined in numerous studies using different instruments or laboratory indices separately. For instance, Soleimanzadeh et al (27) explored the life quality of hemodialysis patients, however, they did not investigate their adherence to treatment. Fouladi et al (28) also studied the prediction of quality of life of hemodialysis patients on the basis of positive psychological variables and mental pathology and traumatology without considering adherence to treatment. Consequently, the present study was carried out considering the impact of adherence to treatment on the quality of life of hemodialysis patients and the necessity of its investigation in a single comprehensive study.

\section{Objectives}

This study sought to determine the quality of life in hemodialysis patients who presented to hemodialysis facilities affiliated to Shahid Beheshti University of Medical Sciences in Tehran on the basis of adherence to treatment.

\section{Patients and Methods}

Study design

This study is a correlational descriptive-analytic investigation.

\section{Sampling and procedures}

The study population included hemodialysis patients in five hospitals affiliated to Shahid Beheshti University of Medical Sciences, Tehran, during 2017. The data were gathered during 8 months from October 2016 to May 2017 in Tehran, Iran. Given that 5 to 10 samples are required for each variable in SEM studies (29), 200 samples were determined as sample volume in this study. The proportion of samples in each hospital was determined with respect to the volume of hemodialysis patients in that center. Availability sampling method was applied to select the patients who observed the inclusion criteria. The inclusion criteria were; patients with chronic renal failure, being a native speaker of Persian language, voluntary participation in the study, and undergoing hemodialysis during the recent week or the recent year. The exclusion criteria were; auditory or verbal/oral problems in patients and lack of inclination for participation.

\section{Ethical issues}

The research followed the tenets of the Declaration of Helsinki. Sampling was done after obtaining approval of Committee of Ethics in Research at Shahid Beheshti University of Medical Sciences under ethics code; IR.SBMU. PHNM.1394.198 and getting written permission from the university authorities. The study units were oriented with the goals and procedures of the study and method of completing the questionnaires and were assured of anonymity and patient information confidentiality. Then, informed written consent was obtained from each patient and they were assured that at the time of publishing the results of the study, their personal information will remain 
confidential. They were told that they could leave the study voluntarily at any stage. They were also informed that leaving the study will not affect the course of their treatment and care. Briefly, this study observed all ethical issues in human research.

\section{Study questionnaires}

The data collection instruments included:

1. Demographic information questionnaire including variables such as age, gender, education level, marital status, occupational status and history of hemodialysis. 2. Kidney Disease Quality of Life Questionnaire (KDQOL) the validity and reliability of which were established by Pakpour et al (30). This inventory includes eight subscales of kidney disease patients. The Health-Related Quality Of Life Questionnaire is the shortened form of 36-item first version which consists of eight categories; physical performance (10 items), role limitation caused by physical problems (4 items), role limitations induced by emotional problems (3 items), social performance (2 items), feeling of emotional well-being ( 5 items), pain (2 items), lethargy (fatigue) and energy (4 items) and perceived general health (5 items). It contains a general item on health. The results obtained from this instrument were finally classified in two sections of summary of physical and mental health status. The second part of the tool is specific to hemodialysis patients and consists of the subscales of signs and problems including muscular and chest pain (12 items), the effect of renal disease on life (8 items), the burden of responsibility of renal disease ( 4 items), occupational status (2 items), cognitive performance (3 items), quality of social interaction (3 items), sexual performance (2 items), sleeping (4 items), social support (2 items), encouragement by hemodialysis ward personnel ( 2 items) and patient satisfaction ( 1 item). This instrument is completed by self-reporting. The items in this tool are responded by direct responses ranging from never $=0$ to always $=100$ (items \#3, 9, 10, 11, 12, 17, 19, 21, $22,23)$, or with reverse responses ranging from always $=0$ to never $=100$ (items $\# 1,2,4-8,13-16,18,20,24)$ or on a vector with a spectrum of $0-100$ (items $\# 13,18$ ). Scoring the items with reverse responses (low scores reflected favorable status) was done by devoting 100 points to "always" and 0 point to "never". The range of scores of any items and scales were set between 0-100 points. Higher scores in any of the items indicated better quality of life. The validity and reliability coefficients of this tool were calculated as 0.77 and 0.83 , respectively.

The standard questionnaire of adherence to treatment in end-stage chronic renal failure patients (ESRD-AQ)

It consists of 5 main sections with 46 items; the first section includes general information ( 5 items), the second section, acceptance of treatment by hemodialysis (14 items), the third section, acceptance of drug therapy ( 9 items), the fourth section, fluid intake constraints (10 items), and the fifth section, the recommended food diet (8 items). The total score of adherence to treatment is estimated as the sum of the points of these 5 sections. The minimum and maximum scores of the questionnaire were predicted as 0 and 1200 points, respectively. A higher score on this tool indicated better adherence to treatment. The scores were finally classified on the basis of Likert scale. As in Kim and colleagues' study, an SD higher and lower than the mean of total adherence to treatment and its categories was rendered as moderate adherence to treatment, scores lower than that as weak adherence to treatment, and scores higher than that as good adherence to treatment. The validity and reliability coefficients of this instrument have been reported by Kim et al (31) as Cronbach's a of $r=0.75$ and test-retest correlation coefficient of $r=0.83$. The validity and reliability coefficients of this inventory were estimated in this study as $r=0.98$ and $r=0.85$, respectively.

\section{Statistical analysis}

The items in each section of the questionnaire were responded by the patients themselves using self-reporting technique during the first 30 minutes after beginning of hemodialysis to stabilize the patient's status and create almost equal conditions for responding. The completion of KDQOL required almost 30 mines while the ESRDAQ was completed in almost 20 minutes. The gathered data were analyzed with SPSS version 18 using descriptive statistics of frequency, mean \pm SD and also inferential statistics including Kolmogorov-Smirnov test to determine normal data distribution, student's $t$ test, oneway ANOVA. In this study $P$ value of less than 0.05 was considered significant.

\section{Results}

Sample characteristics

A total of 200 hemodialysis patients participated in this study. Fifty percent of the samples were male. Most of the respondents (23\%) were 51-60 years old. Other demographic information of the samples is given in Table 1. As can be observed in Table 1, the hemodialysis time of most participants (48\%) of the study was 6-10 months and $64 \%$ of them were married. Furthermore, $26.5 \%$ of the patients had primary school education and $57 \%$ were employed. Table 2 also demonstrates that the mean total score of quality of life of the patients was 46.43 $(25.47 \%)$ and the mean of total score of adherence to treatment was $613.84(29.01 \%)$ (Table 3). There was no significant correlation between demographic variables and quality of life in these patients (Table 4$)(P>0.05)$. Our results (Table 5) further indicated, no significant correlation between demographic variables (education level, occupational status, and hemodialysis time) and adherence to treatment (determination coefficient = 0.04). Moreover, our findings on adherence to treatment and quality of life in hemodialysis patients suggested that adherence to treatment had a significant impact on quality of life $(P<0.05)$ (Table 6$)$. In other words, adherence to treatment can predict the quality of life in hemodialysis patients. 
Table 1. The frequency distribution of the demographic characteristics of the participant

\begin{tabular}{lll}
\hline Variables & Classification & No. (\%) \\
\hline \multirow{2}{*}{ Gender } & Male & $100(50)$ \\
Age & Female & $100(50)$ \\
Marital status & SD \pm Mean & $48.38 \pm 14.89$ \\
& Married & $127(63.5)$ \\
& Single (Widow or divorced) & $73(36.5)$ \\
& Illiterate & $36(18)$ \\
Education status & Elementary & $53(26.5)$ \\
& Diploma & $49(24.5)$ \\
& Bssociate Degree & $31(15.5)$ \\
Occupational & MA & $26(13)$ \\
status & EhD & $4(2)$ \\
& Non-employment & $1(0.5)$ \\
Duration of & $1-5$ & $114(57)$ \\
hemodialysis & $6-10$ & $86(43)$ \\
& $11-15$ & $61(30.5)$ \\
\hline
\end{tabular}

Table 2. The mean and standard deviation of important dimensions of quality of life

\begin{tabular}{ll}
\hline Dimensions of quality of life & Mean (SD) \\
\hline Physical performance & $53.55(22.45)$ \\
Role limitation & $30.65(30.91)$ \\
\hline Pain & $49.86(21.97)$ \\
\hline General health & $57.46(14.86)$ \\
\hline Lethargy and energy & $37.75(17.37)$ \\
Social performance & $47.75(29.88)$ \\
Role emotional & $42.15(33.62)$ \\
Emotional well being & $53.33(15.89)$ \\
\hline Symptoms/problems list & $52.86(14.33)$ \\
\hline Effect of Kidney Disease on daily life & $40.46(18.73)$ \\
\hline Burden of kidney disease & $55.25(17.59)$ \\
Cognitive performance & $48.36(18.37)$ \\
Work status & $38.48(18.04)$ \\
\hline Sexual performance & $43.18(32.66)$ \\
\hline Quality of social Interaction & $47.23(17.86)$ \\
\hline Sleeping & $37.46(14.68)$ \\
\hline Social support & $54.26(24.15)$ \\
\hline Encouragement by hemodialysis & $52.10(20.50)$ \\
\hline Patient satisfaction & $49.33(28.54)$ \\
\hline Total score of quality of life & $46.43(25.47)$ \\
\hline
\end{tabular}

\section{Discussion}

Our findings showed that the mean total score of quality of life in hemodialysis patients was 46.43 (25.47\%) and the mean total score of adherence to treatment was 613.84 (29.01\%). According to these results, the quality of life in these hemodialysis patients was almost favorable. Rodrigues Fructuoso et al (32) stated in their study that the mean total score of quality of life in hemodialysis patients was less than the normal score and the quality of life these patients was low. Nonetheless, Mazairac el al (33) in their study on 570 hemodialysis patients demonstrated that the quality of life's their patients has been within
Table 3. The mean and standard deviation of important dimensions of adherence to treatment

\begin{tabular}{ll}
\hline Dimensions of adherence to treatment & Mean (SD) \\
\hline Drug therapy & $168.09(27.968)$ \\
Fluid intake constraints & $145.00(26.524)$ \\
Food diet & $123.75(32.846)$ \\
Acceptance of treatment by hemodialysis & $177.00(28.725)$ \\
Total score of adherence to treatment & $613.84(29.01)$ \\
\hline
\end{tabular}

Table 4. Linear regression model of the effect of demographic variables on the quality of life score

\begin{tabular}{lccc}
\hline Demographic variables & $\begin{array}{c}\text { Coefficient of } \\
\text { regression }\end{array}$ & Statistics t & $\boldsymbol{P}$ value \\
\hline Age & -0.036 & -0.619 & 0.536 \\
Gender & 3.218 & 1.876 & 0.062 \\
Marital status & 2.122 & 1.065 & 0.288 \\
Education status & -0.184 & -0.287 & 0.774 \\
Occupational status & -1.120 & 0.666 & 0.506 \\
Duration of hemodialysis & 0.013 & 0.056 & 0.955 \\
\hline
\end{tabular}

Table 5. Linear regression model of the effect of demographic variables on the quality of life score

\begin{tabular}{lccc}
\hline Demographic variables & $\begin{array}{c}\text { Coefficient of } \\
\text { regression }\end{array}$ & Statistics t & $\boldsymbol{P}$ value \\
\hline Age & 0.623 & 1.417 & 0.158 \\
Gender & 27.892 & 2.154 & $* 0.032$ \\
Marital status & 24.962 & 1.660 & 0.099 \\
Education status & 3.370 & 0.698 & 0.486 \\
Occupational status & -11.921 & 0.940 & 0.349 \\
Duration of hemodialysis & 1.576 & 0.905 & 0.367 \\
\hline
\end{tabular}

normal limits. Additionally, Tanita et al (34) concluded in their study that the quality of life in hemodialysis patients was relatively high. Likewise, in the study by AL-Jumaih et al (13) conducted in Saudi Arabia, the mean total score of quality of life in hemodialysis patients was high and on the whole, the patients enjoyed appropriate quality of life in all features of physical and mental health and aspects of renal disease. These findings are consistent with our results. The status of adherence to treatment was at the moderate level for most patients. In another study carried out in Italy, it was observed that the rate of adherence to treatment was very weak in most patients (35). Similarly, in another study, the total rate of adherence to treatment in hemodialysis patients was at the moderate level. This is consistent with our results (36). Regression analysis showed that, a significant correlation between total score of quality of life and rate of adherence to treatment $(P<0.01)$ was detected, indicating that adherence to treatment affects quality of life significantly. In the other words, adherence to treatment can predict quality of life in patients undergoing hemodialysis. García-Llana et al (25) indicated that, a positive significant correlation between adherence to treatment, quality of life, physical performance, and the range of physical pain. Nabolsi et al (37) reported a positive significant correlation between quality of life and adherence to diet therapy. This is consistent with our 
Table 6. Correlation between quality of life, distribution of hemodialysis patients

\begin{tabular}{ll}
\hline Variable & Quality of Life \\
\hline Adherence to treatment & $r=0.218$ \\
& $P<0.01$ \\
\hline
\end{tabular}

findings. As shown in Table 4, no significant correlations between any of demographic variables and the score of adherence to treatment were detected. The result of the study by Borji et al (38) suggested a significant correlation between gender and age with the rate of adherence to treatment. Nevertheless, consistent with our findings, other demographic variables like education level, income level, and familial support were not significantly correlated with adherence to treatment. Rafiei Vardjani et al (39) also reported a significant correlation between age and gender with adherence to treatment. On the other hand, the results of this study demonstrated that none of the demographic variables exerted a significant effect on the score of quality of life. García-Llana et al (25) reported a significant correlation only between age and quality of life in hemodialysis patients. In the study by Oliveria et al (40), females obtained a smaller score of physical role compared to males.

\section{Conclusion}

Lack of adherence to treatment is a common problem among hemodialysis patients leading to progress or deterioration of the disease, increased hospital stay and inappropriate response of these patients to hemodialysis. Our results indicated that most patients under study showed adherence to treatment which affected their quality of life significantly. Therefore, identifying the factors that influence the patients' lack of adherence to treatment can be applied to foster the quality of life in these patients.

\section{Limitations of the study}

One of the limitations of this study was that the questionnaires were completed for some patients during dialysis and that the questionnaires were long and exhausting. It is mandatory to consider the conditions and individuals' characteristics when we want to resolve problems and improve the status of adherence to treatment in patients. Nurses can play a significant role in enhancing adherence to treatment in hemodialysis patients through establishing strong supportive relations with patients. Nurses can use the findings of this study to help to promote adherence to treatment in hemodialysis patients. A limitation of our study was small proportion of patients. We suggest multi-centric investigations on this aspect of the renal disease.

\section{Acknowledgments}

This article is part of a nursing doctoral thesis approved by the Shahid-Beheshti University with the ethical code of IR.SBMU.PHNM.1394.198. The authors express their gratitude from participants, officials and staffs of hemodialysis wards.

\section{Authors' contribution}

$\mathrm{MN}$ and MZ; conception, design, acquisition of data, data analysis, interpretation of data, literature review, drafting the article and final approval of manuscript. MI; critical revising for important intellectual content, design, final approval of manuscript. AK; drafting the article and final approval of manuscript. MRA; critical revising for important intellectual content and the study design.

\section{Conflicts of interest}

The authors declare that they have no conflict of interest.

\section{Ethical considerations}

Ethical issues (including plagiarism, data fabrication, double publication) have been completely observed by the authors.

\section{Funding/Support}

None.

\section{References}

1. Benghanem Gharbi M, Elseviers M, Zamd M, Belghiti Alaoui A, Benahadi N, Trabelssi el H, et al. Chronic kidney disease, hypertension, diabetes, and obesity in the adult population of Morocco: how to avoid "over"- and "under"-diagnosis of CKD. Kidney Int. 2016;89:1363-71. doi: 10.1016/j. kint.2016.02.019.

2. Boateng EA, East L. The impact of dialysis modality on quality of life: A systematic review. J Ren Care. 2011;37:190200. doi: 10.1111/j.1755-6686.2011.00244.x.

3. Nobahar M, Tamadon MR. Barriers to and facilitators of care for hemodialysis patients; A qualitative study. J Renal Inj Prev. 2016;5:39-44. doi: 10.15171/jrip.2016.09.

4. Sajadi A, farmihani B, Esmaeil Poor S, Dormanesh B, Zare M. Factors affecting rates of fatigue in patients with chronic renal failure treated with hemodialysis. Intensive Crit Care Nurs. 2011;3:28-33.

5. Stavropoulou A, Grammatikopoulou M, Rovithis M, Kyriakidi K, Pylarinou A, Markaki A. End-stage renal disease patients concerning the provided nursing care. Healthcare. 2017;5:36. doi: 10.3390/healthcare5030036.

6. Sathvik BS, Parthasarathi G, Narahari MG, Gurudev KC. An assessment of the quality of life in hemodialysis patients using the WHOQOL-BREF questionnaire. Indian J Nephrol. 2008;18:141-9. doi: 10.4103/0971-4065.45288.

7. Naderifar M, Zagheri Tafreshi M, Ilkhani M, Kavousi A. The outcomes of stress exposure in hemodialysis patients. J Renal Inj Prev. 2017;6:275-81. doi: 10.15171/jrip.2017.52.

8. Kaba E, Bellou P, Iordanou P, Andrea S, Kyritsi E, Gerogianni $\mathrm{G}$, et al. Problems experienced by haemodialysis patients in Greece. Br J Nurs. 2007;16:868-72. dol: 10.12968/ bjon.2007.16.14.24325.

9. Thomas-Hawkins C. Symptom distress and day-today changes in functional status in chronic hemodialysis patients. Nephrol Nurs J. 2000;27:369.

10. White Y, Grenyer BFS. The biopsychosocial impact of endstage renal disease: the experience of dialysis patients and 
their partners. J Adv Nurs. 1999;30:1312-20.

11. Unruh ML, Hess R. Assessment of health-related quality of life among patients with chronic kidney disease. Adv Chronic Kidney Dis. 2007;14:345-352. doi: 10.1053/j. ackd.2007.07.011

12. Heseih RL, Lee WC, Huang HY, Chang CH. Quality of life and its correlates in ambulatory hemodialysis patients. J Nephrol. 2007;20:731-8. doi: 10.1053/j.ajkd.2006.03.081.

13. AL-Jumaih A, Al-Onazi K, Binsalih S, Hejaili F, Al-Sayyari A. A study of quality of life and its determinants among hemodialysis patients using the KDQOL-SF instrument in one center in Saudi Arabia. Arab J Nephrol Transplant. 2011;4:125-130. doi: 10.4314/ajnt.v4i3.71024.

14. Anees M, Hameed F, Mumtaz A, Ibrahim M, Saeed Khan MN. Dialysis related factors affecting quality of life in patient on hemodialysis. Iran J Kidney Dis. 2011;5:9-14.

15. Al Eissa M, Al Sulaiman M, Jondeby M, Karkar A, Barahmein $M$, Shaheen FAM, et al. Factors affecting hemodialysis patients' satisfaction with their dialysis therapy. Int J Nephrol. 2010:2010:342901. doi: 10.4061/2010/342901.

16. Cohen SD, Patel SS, Khetpal P, Rolf A, Peterson, Paul L. Pain, sleep disturbance and quality of life in patients with chronic kidney disease. Clin J Am Soc Nephrol. 2007;2:919-25. doi: 10.2215/CJN.00820207.

17. Kring DL. Using the revised wilson and cleary modelto explore factors affecting quality of life in persons on hemodialysis [Thesis]. Chapel Hill, USA: University of North Carolina; 2008.

18. Takaki J, Yano E. Possible gender differences in the relationships of self-efficacy and the internal locus of control with compliance in hemodialysis patients. Behav Med. 2006;32:5-11. doi: 10.3200/BMED.32.1.5-11.

19. Gerbino G, Dimonte V, Albasi C, Lasorsa C, Vitale C, Marangella M. Adherence to therapy in patients on hemodialysis. J Ital Nefrol. 2011;28:416-24.

20. Khalil AA, Frazier SK, Lennie TA, Sawaya BP. Depressive symptoms and dietary adherence in patients with end-Stage renal disease. J Ren Care. 2011;37:30-9. doi: 10.1111/j.17556686.2011.00202.x.

21. Denhaerynck K, Manhaeve D, Dobbels F, Garzoni D, Nolte $\mathrm{C}$, De Geest S. Prevalence and consequences of nonadherence to hemodialysis regimens. Am J Crit Care. 2007;16:222-35.

22. Loghman-Adham M. Medication noncompliance in patients with chronic disease:issues in dialysis and renal transplantation. Am J Manag Care. 2003;9:155-71.

23. Pang SK, Ip WY, Chang AM. Psychosocial correlates of fluid compliance among Chinese haemodialysis patients. J Adv Nurs. 2001;35:691-8. doi: 10.1046/j.1365-2648.2001.01901.x.

24. Vaiciuniene R, Kuzminskis V, Ziginskiene E, Skarupskiene I, Bumblyte IA. Adherence to treatment and hospitalization risk in hemodialysis patients. J Nephrol. 2012;25:672-8. doi: 10.5301/jn.5000038.

25. García-Llana H, Remor E, Del Peso G, Selgas R. The role of depression, anxiety, stress and adherence to treatment in dialysis patient's health-related quality of life:a systematic review of the literature. Nefrologia. 2014;34:637-57. doi: 10.3265/Nefrologia.pre2014.Jun.11959.

26. Oliveira A, Schmidt D, Amatneeks M, Santos J, Cavallet L, Michel R. Quality of life in hemodialysis patients and the relationship with mortality, hospitalizations and poor treatment adherence. J Bras Nefrol. 2016;38:411-420. doi: 10.5935/0101-2800.20160066.

27. Soleimanzadeh M, Mousavi S, Chargigan B, Kamangar S, Taheri N. Evaluation of quality of life in hemodialysis patients. J Knowledge Health. 2013;8:119-124.

28. Fouladi Z, Ebrahimi A, Manshei Gh, Afshar H, Steeli M. Predicting the quality of life of hemodialysis patients based on positive psychological variables and psychopathology. Hisp J Behav Sci. 2013;11:6:567-77.

29. Munro BH. Statistical Methods for Health Care Research Philadelphia: Wolters Kluwer Health/Lippincott Williams \& Wilkins; 2013.

30. Pakpour AH, Saffari M, Yekaninejad MS, Panahi D, Harrison AP, Molsted S. Health related quality of life in a sample of iranian patients on hemodialysis. Iran J Kidney Dis. 2010;4:50-9.

31. Kim Y, Evangelista LS, Phillips LR, Pavlish C, Kopple JD. The End-Stage Renal Disease Adherence Questionnaire (ESRD$\mathrm{AQ}$ ):testing the psychometric properties in patients receiving in-center hemodialysis. Nephrol Nurs J. 2010;37:377-93.

32. Rodrigues Fructuoso M, Castro R, Oliveira 1, Prata C, Morgado T. Quality of life in chronic kidney disease. Nefrologia. 2011;31:91-6. doi: 10.3265/Nefrologia.pre2010. Jul.10483.

33. Mazairac AH, Grooteman MP, Blankestijn PJ, Penne EL, van der Weerd NC, den Hoedt $\mathrm{CH}$, et al. Differences in quality of life of hemodialysis patients between dialysis centers. Qual Life Res. 2012;21:299-307. doi: 10.1007/s11136-011-9942-3

34. Tanita T, Rungpetch S, Somkiat V, Cherdchai N. Quality of life and hemoglobin levels of hemodialysis patient at Siriraj Hospital. Siriraj Med J. 2011;63:12-6.

35. Neri L, Martini A, Andreucci VE, Gallieni M, Rocca Rey L, Brancaccio D. Regimen complexity and prescription adherence in dialysis patients. Am J Nephrol. 2011;34:71-6. doi: $10.1159 / 000328391$.

36. Khalili F, Eslami AA, Farajzadeghan Z, Hasan Zadeh A. The Association between social- psychological factors and treatment adherence behaviors among maintenance hemodialysis patients in Isfahan, Iran:a conceptual framework based on Social Cognitive Theory. Health Syst Res. 2011;7:278-90.

37. Nabolsi M, Wardam L, Al-Halabi O. Quality of life, depression, adherence to treatment and illness perception of patients on haemodialysis. Int J Nurs Stud. 2015;21:1-10. doi/10.1111/ijn.12205.

38. Borji M, Otaghi M, Miri M, M Azami, Tavan H. Adherence to treatment in older adults on hemodialysis in Ilam in 201415. NJV. 2016;3:15-26.

39. Rafiei Vardjani L, Parvin N, Mahmoudi Shen Gh, Shariati A, Hasheminia M. Compliance with hemodialysis treatment and its relation with some factors in hemodialysis patients referring to Hajar Medical Center of Shahrekord. J Clin Nurs. 2013;2. 17-25.

40. Oliveira A, Schmidt D, Amatneeks T, Santos J, Cavallet L, Michel R. Quality of life in hemodialysis patients and the relationship with mortality, hospitalizations and poor treatment adherence. J Bras Nefrol. 2016;38:411-420. doi: $10.5935 / 0101-2800.20160066$

Copyright $\odot 2019$ The Author(s); Published by Nickan Research Institute. This is an open-access article distributed under the terms of the Creative Commons Attribution License (http://creativecommons.org/licenses/by/4.0), which permits unrestricted use, distribution, and reproduction in any medium, provided the original work is properly cited. 